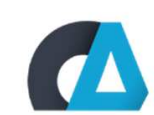

CENTROALGORITMI

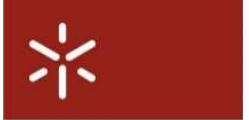

Universidade do Minho

Luís A. M. Barros, V. Monteiro, B. Exposto, A. A. N. Meléndez, J. L. Afonso and J. G. Pinto

"New multifunctional push-pull converter operating with MPPT and integrated energy storage system for PV micro-inverter applications"

IEEE IECON Industrial Electronics Conference, pp.7807-7812, Beijing, China, Oct. 2017.

http://ieeexplore.ieee.org/stamp/stamp.jsp?tp $=$ \&arnumber $=8217368 \&$ isnumber $=8216002$

ISBN: 978-1-5386-1127-2

DOI: $10.1109 /$ IECON.2017.8217368

This material is posted here with permission of the IEEE. Such permission of the IEEE does not in any way imply IEEE endorsement of any of Group of Energy and Power Electronics, University of Minho, products or services. Internal or personal use of this material is permitted. However, permission to reprint/republish this material for advertising or promotional purposes or for creating new collective works for resale or redistribution must be obtained from the IEEE by writing to pubs-permissions@ieee.org. By choosing to view this document, you agree to all provisions of the copyright laws protecting it.

(C) 2017 IEEE 


\title{
New Multifunctional Push-Pull Converter Operating with MPPT and Integrated Energy Storage System for PV Micro-Inverter Applications
}

\author{
Luis A. M. Barros ${ }^{1}$, J. G. Pinto ${ }^{1}$, Vítor Monteiro ${ }^{1}$, Bruno Exposto ${ }^{1}$, João L. Afonso ${ }^{1}$, Andrés A. Nogueiras Meléndez \\ ${ }^{1}$ ALGORITMI Research Centre - University of Minho, Guimarães - Portugal \\ ${ }^{2}$ Departamento de Tecnología Electrónica - University of Vigo, Vigo - Spain \\ ${ }^{1}\left\{\right.$ luis.barros | gabriel.pinto | vitor.monteiro | bexposto | joao.1.afonso\}@algoritmi.uminho.pt ${ }^{2}$ aaugusto@uvigo.es
}

\begin{abstract}
This paper presents a novel multifunctional push-pull converter for micro-inverter applications, used to interface photovoltaic (PV) modules and an battery energy storage system with the power grid (PG). The push-pull DC-DC power converter requires only two switching devices. It uses a specific algorithm to control the batteries charging process, preserving their lifetime, and also to operate as maximum power point tracker, optimizing the energy production from the PVs modules. The push-pull DC-AC power converter operates in coordination with the DC-DC converter, injecting all available energy from the PVs modules into the PG. If the produced energy exceeds the consumed energy, the surplus is used to charge the batteries for latter consumption. The proposed topology aims to contribute to the technological development in terms of power converters for micro-inverter applications. Throughout the paper is given a detailed explanation on the principle of operation of the new topology, as well as on the proposed digital control algorithm.
\end{abstract}

Keywords-Battery Energy Storage System, Micro-Inverter, MPPT, Photovoltaics, Power Electronics Converters, Power Grid Interface, Push-Pull Converter.

\section{INTRODUCTION}

In recent years it has been done a major investment in the development and dissemination of renewable energy sources all over the world, in order to reduce the fossil fuels consumption [1], [2]. In Portugal, the policies encourage the renewable energy (RE) production for self-consumption purposes, improving energy efficiency, since the place of production is close to the place of consumption, being equally true in other countries. For instance, the licensing process for solar photovoltaic installations up to $1.5 \mathrm{~kW}$ is very simplified, however, the surplus of energy production is injected into the power grid without any type of payback [3]. Therefore, it is advantageous to include a system to store the energy production surplus for later use.

Smart grids emerge as an innovative concept, to improve efficiency, reliability, and security, and also to enable a dynamic integration of RE sources. In this sense, it becomes evident that houses and companies can assume the role of energy consumers and producers (prosumers) [4]. In addition, this model will also enable the energy management, providing financial benefits for the users, evidencing the crucial role that energy storage technologies play in this new paradigm [5].

Micro-inverters are compact power converters used to interface photovoltaics (PVs) modules with the power grid (PG), allowing a continuous extraction of energy from each PV module, without influencing the extraction of energy from adjacent PV modules. In addition, they allow the modularization and expansion of the PVs system in a simple way, without having to re-scale the main inverter. Moreover, micro-inverters can have communication interfaces, which allow continuous monitoring of the energy produced in each module, facilitating the detection of any problem in the installation [1]. Typically, these micro-inverters are constituted by a high-frequency DC-DC power converter followed by a DC-AC power converter. However, the purpose of micro-inverters available in the market is exclusively the injection of power from the PVs modules into the PG, not allowing the interface with a local energy storage system, which is a disadvantage when the production exceeds the consumption.

In the literature there are some micro-inverter topologies used in PVs modules, as well as new control algorithms. The most common converter used in the DC-DC stage of micro-inverters is the flyback [6], [7]. New flyback topologies that mitigate some intrinsic problems are proposed in [8], [9]. As presented in [10], a critical disadvantage is related on the conventional flyback topology with the switching device state as OFF, in which the primary current (in the PV module side) is interrupted, i.e., during this period the power extracted from the PV module is null. To tackle this problem, a current-fed push-pull topology is presented in [11], avoiding the transformer saturation and, since it is a current-fed converter, the power extracted from the PV module is not interrupted. Another advantage of this topology is the fact that both switching devices are referenced to the ground, which simplifies the drive circuit when compared to other topologies, like the full-bridge [12], [13] or the half-bridge converters [14], [15]. However, none of these topologies allow the interface with a stage for local energy storage. For this purpose, a new multifunctional current-fed push-pull topology is presented in this paper.

Fig. 1 shows the electrical schematic of the proposed topology. As it can been seen, by adding an additional diode $\left(D_{5}\right)$, an additional capacitor $\left(C_{3}\right)$ and a proper control algorithm, it is possible to use the same DC-DC converter to the simultaneous interface of the PVs modules with the DC-AC converter and with a battery energy storage system (BESS). With that, it is intended to innovate in the micro-inverter concept, presenting a new topology with a BESS for PV applications. 


\section{PROPOSED TOPOLOGY}

\section{A. System Architecture}

The proposed topology for micro-inverter applications offers a new solution for today's needs. This topology is capable not only to extract energy from a PV module to inject into the PG, but also store energy into BESS. The topology is comprised by a DC-DC power converter followed by a DC-AC converter. The DC-DC converter is responsible to interface the PV modules with the BESS and the DC-link of the DC-AC converter. For a proper operation, this converter is controlled using a Maximum Power Point Tracker (MPPT) algorithm that is responsible to find the Maximum Power Point (MPP) and to maintain the DC-DC converter operating in this point. Additionally, it is also implemented a battery charging algorithm to preserve their lifetime. The main purpose is not to perform a complete battery charging process, but store the surplus of energy production along the daylight hours to use later during the night. During this charging mode the current and the voltage in the batteries are constantly monitored in order to comply with the values recommended by the manufacturer. The full battery charging algorithm is activated periodically to maintain the battery state of health. Regarding the DC-AC power converter, its main purpose is to inject the energy provided by the PV module, or by the BESS, into the PG, more at the point of consumption. Taking into account the system elements and their possible interaction modes, it is possible to define the following operation modes: Mode 1 (PV to PG) -When the consumed power exceeds the power provided by the PV modules, all the extracted power is injected into the PG; Mode 2 (PV to PG and to BESS) - When the power produced exceeds the consumed power, the surplus is used to charge the BESS; Mode 3 (PV to BESS) - If there is no consumption in the home (or during power grid outages) and the BESS is not fully charged, then the power from the PV module is used to charge the BESS. With these operation modes, it is possible to reduce the energy dependence from the PG and, consequently, ensure financial advantages. In order to control the energy flow during these operation modes, it is important consider the sequence of gate signals applied to the MOSFETs $S_{I}$ and $S_{2}$. That sequence is represented in Fig. 2 as well as the physical element that receives the energy at each instant. These signals do not have a fixed switching frequency or a fixed duty-cycle, i.e., they can be adjusted in accordance with the control algorithm to charge the BESS. It is important to note that the MPPT algorithm will also influence the duty-cycle value. According to Fig. 2, the two last pulses correspond to the amount of energy injected into the PG. It is mandatory that these two last pulses have the same duration to avoid the transformer saturation.

\section{B. Principle of Operation}

In order to understand the principle of operation presented in Fig. 3 , it will be considered that all capacitive elements $\left(C_{1}, C_{2}\right.$ and $C_{3}$ ) are initially fully charged. Thus, at time $t_{0}$, the MOSFETs $S_{1}$ and $S_{2}$ are turned ON (Fig. 3 (a)). At this time, the input current, $i_{L}$, flows through the primary transformer windings, $L_{p 1}$ and $L_{p 2}$, and, as the magnetic flux induced by the primary windings has opposite directions, a magnetic shortcut is created on the primary windings of the transformer. Consequently, the inductive element $L_{l}$ will be in parallel with the power supply $V_{i n}$, storing the energy coming from it. At the

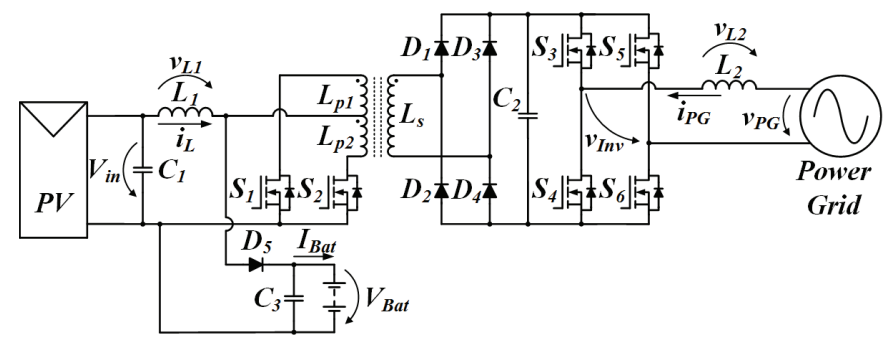

Fig. 1. Electrical diagram of the proposed topology.

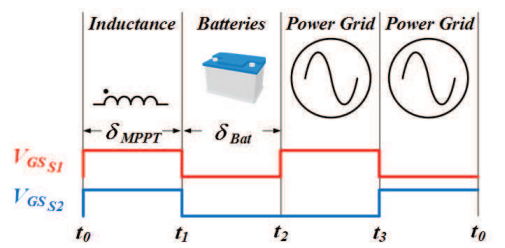

Fig. 2. Gate signals sequence and physical element that receives energy.

next instant $\left(t_{1}\right)$, both the push-pull MOSFETs are turned OFF (Fig. 3 (b)), allowing the power supply and $L_{l}$, previously charged, to charge the BESS and the capacitor $C_{3}$, that will work as a low-pass filter, maintaining the BESS charging current almost constant. As it can be seen, the use of these two modes, in a sequential manner, will impose the primary side of the push-pull to behave as a conventional non-isolated DC-DC step-up, interfacing the PV modules with the BESS.

The following two operation modes are related with the energy sent to the transformer secondary winding, $L_{s}$. During the third stage of operation, in $t_{2}$, only the MOSFET $S_{l}$ is turned ON (Fig. 3 (c)), allowing $i_{L}$ to flow through $L_{p 1}$ having a voltage equal to the sum of $V_{\text {in }}$ with $v_{L}$. Consequently, an induced voltage will appear in $L_{s}$, affected by the transformation ratio, specifically in this case of $1: 10$. The energy sent to the secondary side of the transformer will be injected into the PG and a small part to recharge capacitor $C_{2}$. Finally, at time $t_{3}$ the MOSFET $S_{2}$ is turned ON and the MOSFET $S_{l}$ is turned OFF (Fig. $3(\mathrm{~d})$ ). Once again, $i_{L}$ will pass through $L_{p 2}$ which will induce a voltage in $L_{s}$ proceeding to send power to the PG. This last mode of operation is similar to the third stage $\left(t_{2}\right)$, being the current in $L_{p 2}$ the responsible for inducing the voltage in the $L_{s}$. It should be noted that, during all the stages, the DC-AC power converter needs to inject energy into the PG.

Additionally, when Mode 1 is active, it should be noted that the MOSFETs S1 and S2 may have to withstand a voltage four times higher than the Vin, a consideration when considering the size of the components.

\section{CONTROL AlgorithmS}

The proposed topology requires an accurate control system in order to guarantee the correct and continuous operation of the micro-inverter. The control algorithm can be divided in four main blocks: MPPT; BESS charging; DC-link voltage control; Current control for the DC-AC power converter.

\section{A. MPPT Algorithm}

Ideally, the PV module should always operate at nominal power. However, the power of solar cells is influenced by external factors such as radiation, temperature and incident shadows [16]. These factors cause variations in the available 


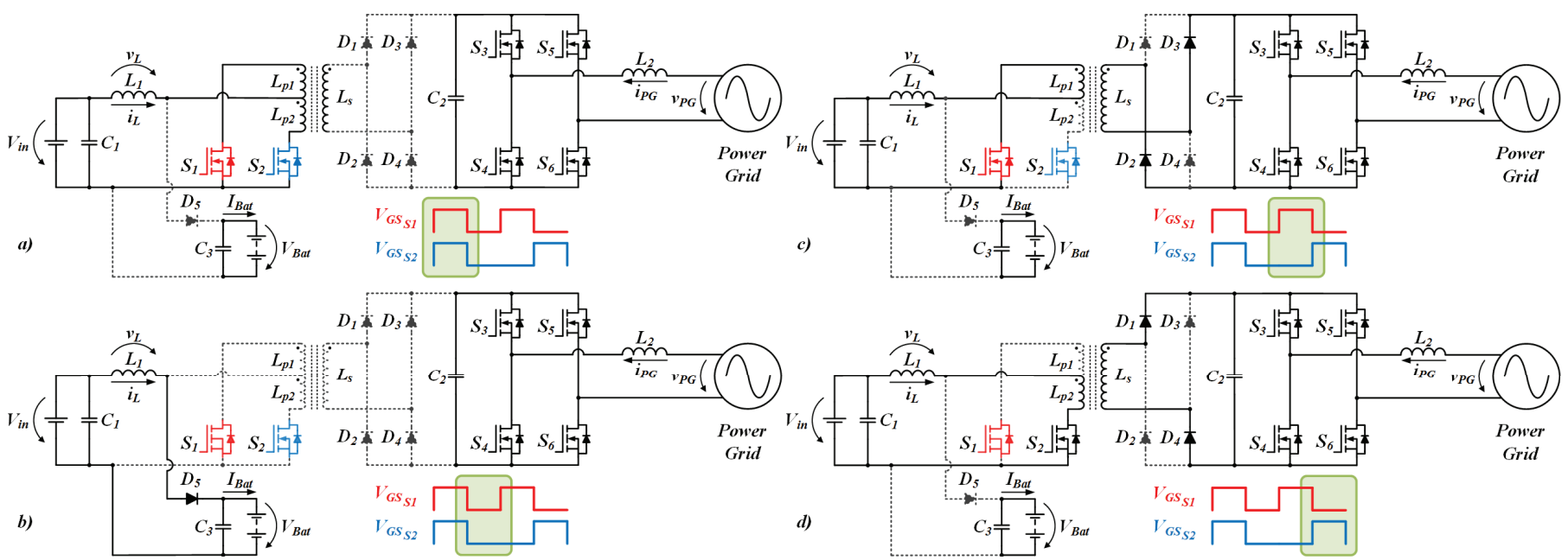

Fig. 3. Operation principle stages: (a) MOSFETs S1 and S2 turned ON creating a magnetic short-cut into the high-frequency transformer; (b) MOSFETs S1 and S2 are turned OFF, charging the BESS; (c) only MOSFET S1 is turned ON, sending energy to the secondary winding of the transformer by $L_{p 1}$; (d) Only MOSFET S2 is turned $\mathrm{ON}$, sending energy to the secondary winding of the transformer by $L_{p 2}$.

currents and/or voltages, which will consequently affect the total power generated by the PV module. Therefore, must be used MPPT control algorithms, with different levels of complexity, as presented in [17]-[20]. In the scope of this paper is used the incremental conductance MPPT algorithm, which is based on the characteristic curve of the PV module to find the MPP [17]. In fact, when the system is operating at the MPP, it the derivative of the output power of the module, in relation to the voltage, is zero.

\section{B. BESS Charging Control Algorithm}

The implementation of a control algorithm for charging the BESS is an essential to extend the battery lifetime. As presented in [21], there are numerous battery charging algorithms with different levels of complexity and related with the batteries technology. Considering the application presented in this paper, and for demonstration and validation purposes, the constant-current followed by constant-voltage algorithm was selected [21]. This algorithm consists of two stages of charging, beginning with constant current until the BESS's voltage reaches the nominal value, passing to a constant voltage until the current reaches a value close to zero.

\section{DC-link Voltage and Current Reference}

One of the main features of a conventional micro-inverter is the injection of energy into the PG. For that, a constant monitoring and DC-link regulation is a crucial aspect to guarantee its correct operation. The DC-link voltage must be higher than the peak-value of the PG voltage.

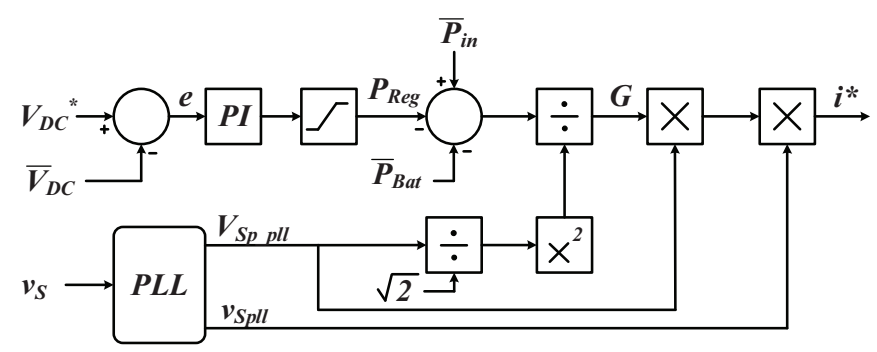

Fig. 4. Block diagram of the reference current calculation to inject into the PG.
Fig. 4 shows a block diagram of the reference current calculation to inject in the PG. The first step of this control consists in the DC-link voltage control. For an accurate DC-link voltage control is implemented a sliding average across such voltage, $\bar{V}_{D C}$, which is subtracted to the reference voltage, $V_{D C}{ }^{*}$, resulting in a voltage error, $e$. This variable is used in a Proportional Integral (PI) controller, which calculates the required power, $P_{R E G}$, to maintain the DC-link voltage controlled [22]. After that, the $P_{R E G}$ power is used to calculate a reference current, $i^{*}$, to inject energy into the PG. The input power $\bar{P}_{I N}$ is obtained through a sliding average that represents the active power supplied by the PV module. Posteriorly, the average power used to charge the BESS $\left(\bar{P}_{B a t}\right)$ and the $P_{R E G}$ are subtracted to the $\bar{P}_{I N}$. The resultant value, which represents the power to be injected into the PG is divided by the rms square value of the $\mathrm{PG}$ voltage in order to determine the equivalent conductance $G$ represented in (1).

$$
\mathrm{G}=\frac{\overline{P_{I N}}-\overline{P_{B a t}}-P_{R E G}}{\left(\frac{V_{S p_{P L L}}}{\sqrt{2}}\right)^{2}}
$$

As it can be seen, it is used a phase-locked loop algorithm $(P L L)$ to obtain the value of the PG amplitude, $V_{S P_{-} P L L}$, which is used in a way to determine the effective value of the PG. The reference current, $i^{*}$, results from the multiplication of the resulting unitary signal of the PLL algorithm, $v_{S_{-} P L L}$, with the conductance $G$ according to (2).

$$
i^{*}=G v_{S_{P L L}} V_{S p_{P L L}}
$$

Finally, the reference current, $i^{*}$, will be used in the current control algorithm to the DC-AC power converter synthetize a sinusoidal output current, $i_{P G}$.

\section{Current Control for the DC-AC Power Converter}

For the micro-inverter correct operation, the DC-AC power converter must be able to synthesize a current with low harmonic content and with a phase of $180^{\circ}$ in relation to the fundamental component. The current control technique for the DC-AC takes advantage of the feedback from the control system, creating a closed loop, which allows to determine the value of the voltage 
to be generated by the converter to obtain the desired output current. Numerous current control techniques have been developed, some of them presented in [22]-[27]. The predictive control technique presents interesting characteristics when compared to the other ones, since it is based on the electrical model of the system to predict the future behavior of the controlled variable. The effectiveness of this control technique is directly influenced by the quality of the used system model [26]. By analyzing the system model shown in Fig. 1, it is possible to visualize that the output voltage of the inverter, $v_{i n v}$, is equal to the sum of the PG voltage, $v_{P G}$, and the voltage drop to the terminals of the coupling inductor, $v_{L}$. Since the internal resistance of the coupling inductor has relatively low values, it is possible to neglect it, thus obtaining (3) [22].

$$
v_{i n v}=v_{L 2}+v_{P G}
$$

After replacing the inductor voltage, $v_{L 2}$, by its characteristic equation, is obtained (4). The current error, $i_{\text {error }}$, is calculated as the difference between the $i^{*}$ and the $i_{P G}$, as (5). Introducing the $i_{\text {error }}$, determined in (5), in the electric model of the system, and combining with (4), it is possible to get (6).

$$
\begin{gathered}
v_{i n v}=L \frac{d i_{P G}}{d t}+v_{P G} \\
i_{\text {error }}=i^{*}-i_{P G} \\
v_{\text {inv }}=L \frac{d i^{*}}{d t}-L \frac{d i_{\text {error }}}{d t}+v_{P G}
\end{gathered}
$$

In order to allow the processing of the previous equations by means of a microcontroller, it is necessary to convert it to a discrete domain. Considering a high sampling frequency $f_{S}=1 / T_{S}$, it can be considered that the variation of the error current $\left(\Delta i_{\text {error }}\right)$, in a given short sampling interval $d t$, is practically constant, resulting in (7).

$$
v_{i n v}[k]=v_{P G}[k]+\frac{L}{T_{S}}\left(2 i^{*}[k]-i^{*}[k]-i_{P G}[k]\right)
$$

The $v_{i n v}$ is the reference voltage used to control the DC-AC power converter, where a $50 \mathrm{kHz}$ unipolar SPWM triangular carrier was used, providing a $100 \mathrm{kHz}$ resulting output frequency.

\section{Simulation RESUlts}

In this section are discussed the simulation models of the proposed architecture, as well as the corresponding results. In order to achieve a simulation model the most accurate as possible, some non-ideal aspects of the system were considered in the model. One important fact to mention is the batteries electrical model. Therefore, it was tried to model the battery behavior with an equivalent electrical model, which is helpful to make small adjustments on the control algorithms. The core part of the proposed micro-inverter is the DC-DC converter, where is implemented the MPPT and the batteries charging control algorithm. In the simulation model were considered the Kyocera KC200GHT PV module, whose maximum power is $200 \mathrm{~W}$. It should be noted that initially, all the passive components that constitute the system are discharged and the PV module is operating under the Standard Test Conditions (STC) [1], initiating the MPPT algorithm in order to extract the maximum power of the PV module and, in parallel, the algorithm of the BESS charging.

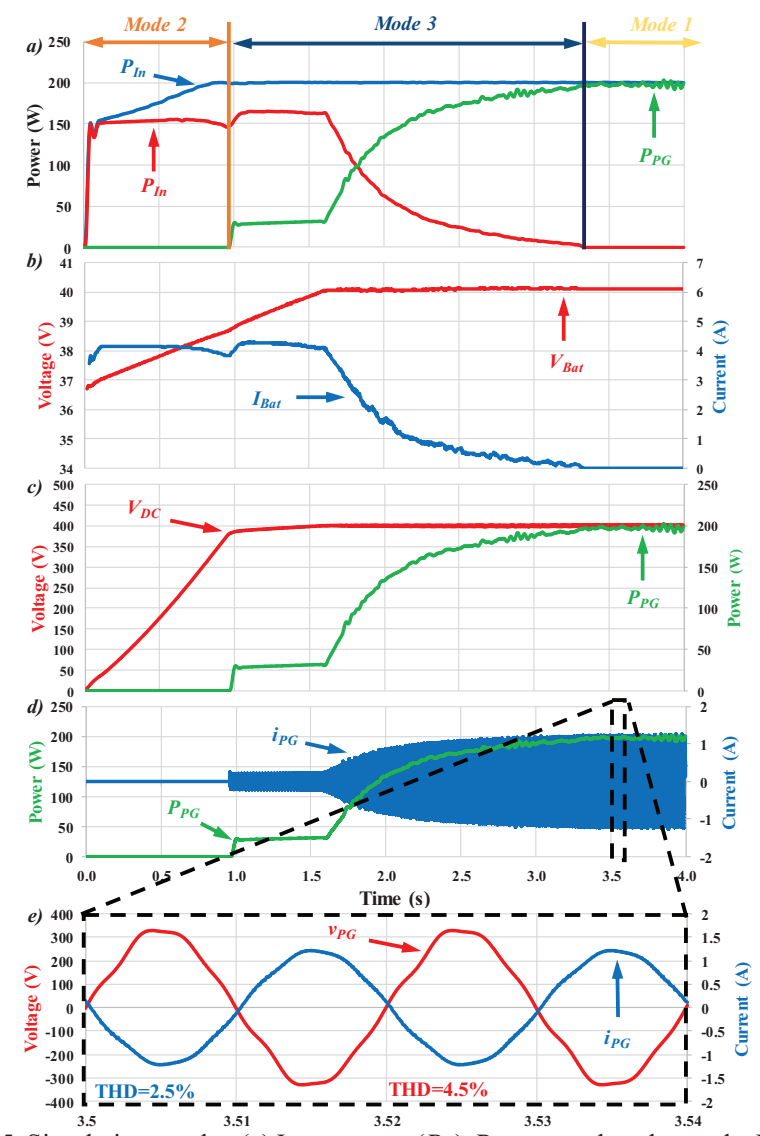

Fig. 5. Simulation results: (a) Input power $\left(P_{i n}\right)$, Power used to charge the BESS $\left(P_{B a t}\right)$ and injected power into PG $\left(P_{P G}\right)$; (b) Voltage $\left(V_{B a t}\right)$ and current $\left(I_{B a t}\right)$ during the BESS charge; (c) DC bus regulation, showing the voltage on the DC bus $\left(V_{D C}\right)$ and the power injected into the PG; (d) Current $\left(i_{P G}\right)$ produced by the DC-AC power converter and power injected into the PG; (e) Detail current $\left(i_{P G}\right)$ produced by the DC-AC power converter and the voltage $\left(v_{P G}\right)$ from the $\mathrm{PG}$.

\section{A. Validation of the Proposed Power Converter}

When allowed by operating conditions, the algorithm responsible for the injection of energy into the PG is initialized. As aforementioned it is possible to identify the three operation modes. Mode 2 - In the initial phase, is initialized a pre-load of the DC-link voltage and charging the BESS. In addition, the correct operation of the MPPT algorithm can be verified, once the MPP available in the PV module $(200 \mathrm{~W})$ is being extracted. In this operation mode, part of the energy from the PV module is sent to charge the BESS and a remaining portion to charge the DC-link capacitor, $C_{3}$. Mode 3 - This operation mode starts when the BESS are not fully charged and the DC-link voltage reaches a minimum value that allows to inject power into the PG. These operation modes are shown in Fig. 5 (a) as well as the evolution over time of all the powers of the micro-inverter: $P_{\text {in }}$ symbolizes the input power of the micro-inverter; $P_{B a t}$ denotes the power available for charging the BESS; $P_{P G}$ represents the PG injected power. Thus, as shown in Fig. 5 (a), the effectiveness of the system to maintain a constant charge $P_{B a t}$ of the BESS can be verified, at the same time that the injection of power into the PG is performed. Mode 1 - Once the BESS are fully charged, the micro-inverter sends all the power extracted from the PV module into the PG, allowing to verify the correct operation of the MPPT algorithm. In Fig. 5 (b), it can be seen in more detail, the BESS control algorithm performance. The 

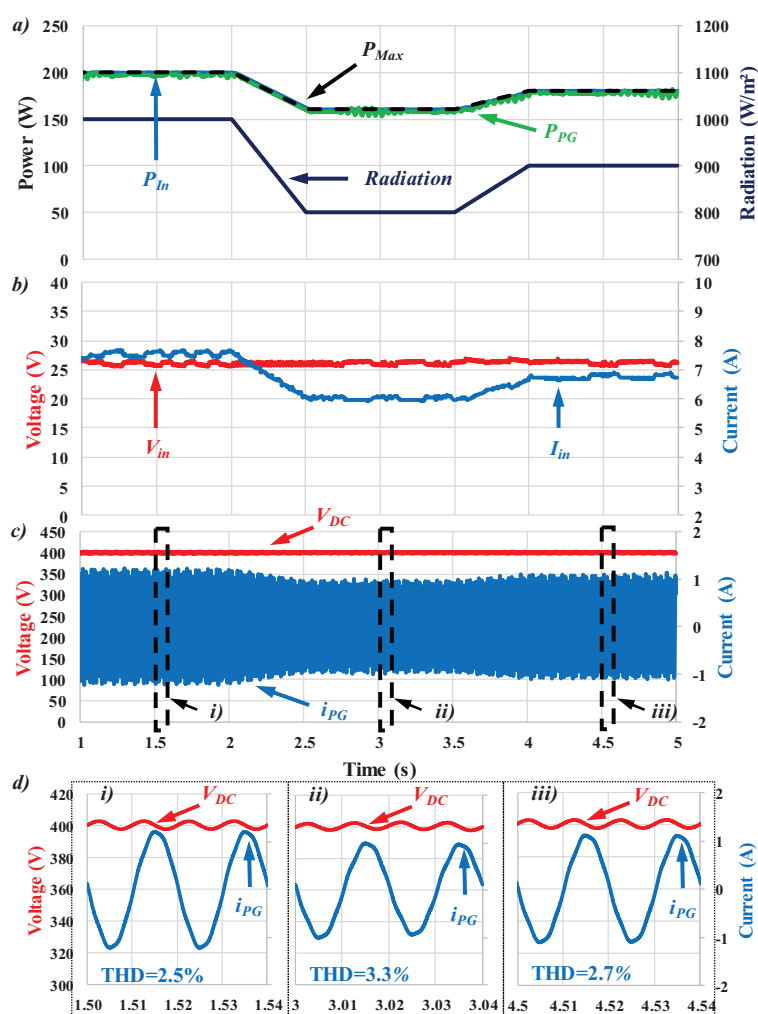

Fig. 6. Simulation results of the influence of radiation on the produced energy: (a) Input power $\left(P_{i n}\right)$ and injected power $\left(P_{P G}\right)$; (b) Input voltage $\left(V_{i n}\right)$ and input current $\left(I_{i n}\right)$ of the micro-inverter; (c) Current synthesized by the DC-AC converter $\left(i_{P G}\right)$ and DC bus voltage $\left(V_{D C}\right)$; (d) Details of $i_{P G}$ and $V_{D C}$ under different operation power values.

figure shows the BESS charging process. As intended, it can be seen that the BESS are initially charged with a constant current until a nominal voltage of $40.2 \mathrm{~V}$. After that, constant voltage control is initialized until the $I_{B a t}$ reaches a residual value close to zero. Parallel to the BESS charging process, the DC-link voltage control is activated, as shown in Fig. 5 (c).

The variation of the injected power can be visualized in accordance with the voltage value of the DC-link. In an initial phase, the DC-link capacitors charging is initialized. When the DC-link voltage reaches a stipulated minimum value, in this case $380 \mathrm{~V}$, the DC-AC converter operation is activated, proceeding to the injection of power into the PG. At this moment, the DC-link voltage and current reference algorithm is initialized, synthesizing a sinusoidal current with a phase of $180^{\circ}$ in relation to the fundamental component of the $\mathrm{PG}$ voltage and regulating the DC-link into $400 \mathrm{~V}$. Fig. 5 (d) shows the $i_{P G}$ produced by the DC-AC power converter and the $P_{P G}$. As it is perceptible, the amplitude of $i_{P G}$ varies according to the available power for injection into the $\mathrm{PG}$, obtaining a maximum amplitude when all the power provided by the PV module is delivered to the PG. Fig. 5 (e) shows in detail the waveforms of the PG current, $i_{P G}$, and voltage, $v_{P G}$.

\section{B. Validation of the MPPT Algorithm}

The MPPT algorithm was validated under different conditions of operation, being presented some simulations results in Fig. 6 and Fig. 7. As previously mentioned, the power available in the PV module is directly related to external factors, such as incident solar radiation and the temperature of the solar
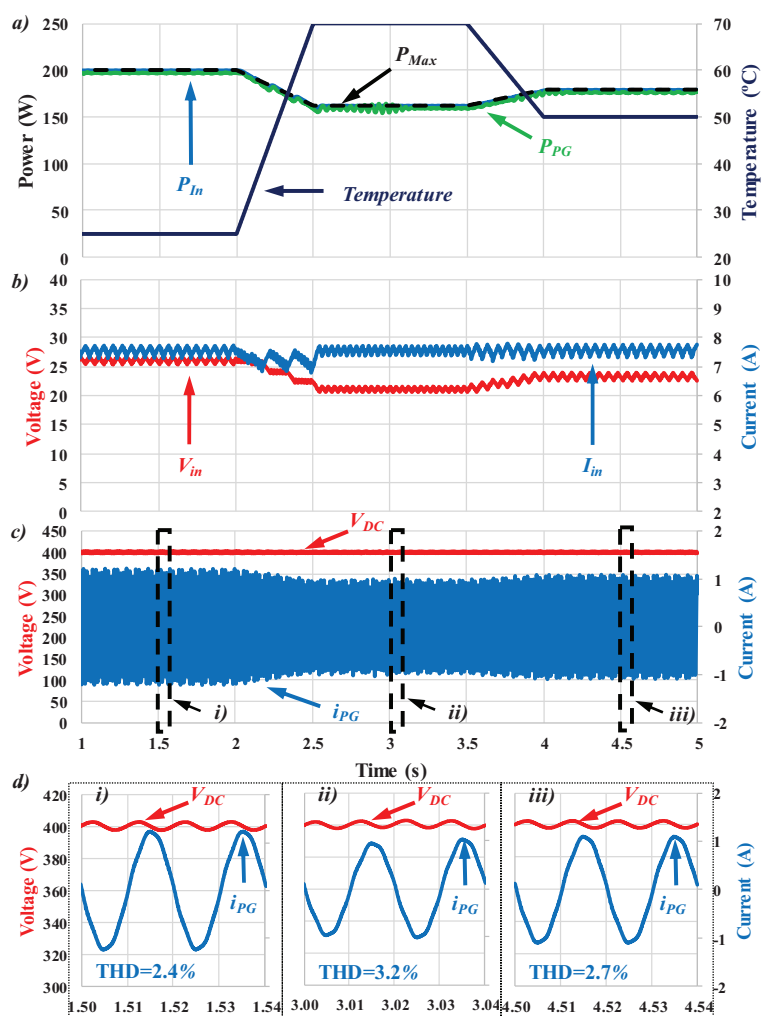

Fig. 7. Simulation results of the influence of the temperature on produced energy: (a) Input power $\left(P_{i n}\right)$ and injected power $\left(P_{P G}\right)$; (b) Input voltage $\left(V_{\text {in }}\right)$ and input current $\left(I_{i n}\right)$ of the micro-inverter; (c) Current produced by the DC-AC converter $\left(i_{P G}\right)$ and DC-link voltage $\left(V_{D C}\right)$; (d) Details of $i_{P G}$ and $V_{D C}$ under different operation power values.

photovoltaic cells. With the purpose of validate the MPPT algorithm implemented in the proposed topology, it was considered an incident radiation variation from $1000 \mathrm{~W} / \mathrm{m}^{2}$ to $800 \mathrm{~W} / \mathrm{m}^{2}$ and later to $900 \mathrm{~W} / \mathrm{m}^{2}$. As expected, such variation is reflected on the $P_{\text {in }}$ of the micro-inverter and hence the $P_{P G}$, as can be seen in Fig. 6 (a). As expected, the variation of the radiation incident on the PVs modules influences, essentially, the current generated by the PV module, maintaining practically constant the generated voltage average value at its MPP, as can be verified with the simulation result obtained in Fig. 6 (b). Consequently, the output power variation is reflected in the amplitude of the current produced by the DC-AC converter. This variation can be seen in Fig. 6 (c). It can also be seen that, even with these variations, the DC-link voltage regulation works properly, maintaining a constant voltage on the DC-link, ensuring the correct operation of the micro-inverter. Finally, Fig. 6 (d) shows the correct operation of the DC-AC converter, i.e., synthetizing a sinusoidal current, $i_{P G}$, with low harmonic content. In a similar way, it was considered a variation in terms of operating temperature of the photovoltaic solar module, from $25^{\circ} \mathrm{C}$ to $70^{\circ} \mathrm{C}$ and later to $50^{\circ} \mathrm{C}$, as shown in Fig. 7. Such variation was considered in order to analyze the behavior of the control algorithms under these operating conditions. The realization of this simulation is especially important to predict if the system is able to keep the DC-link voltage constant and a continuous injection of energy into the $\mathrm{PG}$, even with an $V_{\text {in }}$ lower than the nominal. The temperature variation and its influence on the system powers can be seen in Fig. 7 (a). As expected, the temperature directly influences the voltage of the 
PVs modules, and this influence is reflected in the $P_{i n}$. As shown in Fig. 7 (b), under STC conditions, the system operates at its nominal conditions, and as the temperature increases the voltage decreases. The MPPT algorithm is able to overcome the adversities, maintaining an extraction close to the MPP available by the PV module at each moment. Likewise, the micro-inverter is able to maintain its functionality by keeping the $V_{D C}$ regulated and, consequently, the DC-AC converter operates properly as shown in Fig. 7 (c). Performing an analysis of the waveforms during certain time periods, it can be concluded that regardless of the operating conditions, the control algorithms work properly, maintaining: a continuous extraction of the maximum power provided by the PV module; a voltage on the DC-link practically constant and close to its stipulated reference value; a continuous injection of energy into the PG with a sinusoidal current and low harmonic content.

\section{CONCLUSION}

This paper presents an innovative multifunctional push-pull converter for micro-inverter applications, used to interface a PV module and a battery energy storage system with the power grid. The proposed topology is able to control the batteries charging process and find the MPP simultaneously, with only two switching devices. The principle of operation and the proposed control algorithm are described in detail along the paper. Simulation results were obtained to prove the correct operation of the proposed topology with the implemented control algorithm. Such results were obtained considering the influence of radiation and temperature on the produced energy. It was possible to verify the proposed operation modes, demonstrating the versatility of the micro-inverter in providing power to the BESS and/or to the PG.

\section{ACKNOWLEDGEMENT}

This work has been supported by COMPETE: POCI-010145-FEDER-007043 and FCT - Fundação para a Ciência e Tecnologia within the Project Scope: UID/CEC/00319/2013. This work is financed by the ERDF - European Regional Development Fund through the Operational Programme for Competitiveness and Internationalisation - COMPETE 2020 Programme, and by National Funds through the Portuguese funding agency, FCT - Fundação para a Ciência e a Tecnologia, within project SAICTPAC/0004/2015- POCI- 01-0145FEDER-016434.

\section{REFERENCES}

[1] A. Luque and S. Hegedus, Handbook of photovoltaic science and engineering. John Wiley \& Sons, 2011.

[2] I. Irena, "Renewable energy technologies: Cost analysis series," Concentrating solar power, 2012.

[3] MINISTÉRIO DO AMBIENTE ORDENAMENTO DO TERRITÓRIO E ENERGIA, "Decreto-Lei n. ${ }^{\circ}$ 153/2014 de 20 de outubro," Diário da República, vol. 1. ${ }^{\mathrm{a}}$ série, no. - N. ${ }^{\circ} 202$, pp. 5298-5311, 2014.

[4] E. SmartGrids, "SmartGrids - Strategic Research Agenda Update of the SmartGrids SRA 2007 for the needs by the year 2035," Mar. 2012.

[5] V. C. Gungor, D. Sahin, T. Kocak, S. Ergut, and C. Buccella, "Smart grid technologies: Communication technologies and standards," IEEE Trans. Ind. Informat., vol. 7, no. 4, pp. 529-539, 2011.

[6] A. C. Nanakos, G. C. Christidis, E. C. Tatakis, "Weighted efficiency optimization of flyback microinverter under improved boundary conduction mode (i-BCM)," IEEE Trans. Power Electron., vol. 30, no. 10 , pp. 5548-5564, 2015.
[7] D. A. Ruiz-Caballero and I. Barbi, "A new flyback-current-fed push-pull DC-DC converter," IEEE Trans. Power Electron., vol. 14, no. 6, pp. 1056-1064, 1999

[8] M. A. Rezaei, K.-J. Lee, and A. Q. Huang, "A high-efficiency flyback micro-inverter with a new adaptive snubber for photovoltaic applications," IEEE Trans. Power Electron., vol.31, 2016.

[9] W.-J. Cha, Y.-W. Cho, J.-M. Kwon, and B.-H. Kwon, "Highly efficient microinverter with soft-switching step-up converter and single-switchmodulation inverter," IEEE Trans Ind. Electron., vol. 62, no. 6, pp. 3516 3523, 2015.

[10] L. A. G. Rodriguez and J. C. Balda, "A comparison of isolated DC-DC converters for microinverter applications," IEEE APEC Applied Power Electronics Conference and Exposition, pp. 2084-2091, 2013.

[11] C. Felgemacher, P. Jaeger, A. Kobeissi, J. Pfeiffer, "Design of photovoltaic microinverter for off-grid and grid-parallel applications," CIPS International Conference on Integrated Power Systems, pp.1-6, 2014.

[12] J. R. Gazoli, M. G. Villalva, T. G. Siqueira, and E. Ruppert, "Microinverter for integrated grid-tie PV module using resonant controller," Power and Energy Society General Meeting, 2012, pp. 1-8.

[13] S. Poshtkouhi, M. Fard, H. Hussein, L. M. Dos Santos, O. Trescases, M. Varlan, T. Lipan, "A dual-active-bridge based bi-directional microinverter with integrated short-term li-ion ultra-capacitor storage and active power smoothing for modular PV systems," Applied Power Electronics Conference and Exposition (APEC), pp.643-649, 2014.

[14] D. Cao, S. Jiang, F. Z. Peng, Y. Li, "Low cost transformer isolated boost half-bridge micro-inverter for single-phase grid-connected photovoltaic system," IEEE APEC Applied Power Electronics Conference and Exposition, pp.71-78, 2012.

[15] S. Jiang, D. Cao, Y. Li, and F. Z. Peng, “Grid-connected boost-half-bridge photovoltaic microinverter system using repetitive current control and maximum power point tracking," IEEE Transactions on power Electronics, vol. 27, no. 11, pp. 4711-4722, 2012.

[16] H. Patel and V. Agarwal, "MATLAB-based modeling to study the effects of partial shading on PV array characteristics," IEEE transactions on energy conversion, vol. 23, no. 1, pp. 302-310, 2008.

[17] T. Esram and P. L. Chapman, "Comparison of photovoltaic array maximum power point tracking techniques," IEEE Transactions on energy conversion, vol. 22, no. 2, pp. 439-449, 2007.

[18] N. Femia, G. Petrone, G. Spagnuolo, and M. Vitelli, "Optimization of perturb and observe maximum power point tracking method," IEEE transactions on Power Electronics, vol. 20, no. 4, pp. 963-973, 2005.

[19] A. K. Abdelsalam, A. M. Massoud, S. Ahmed, and P. N. Enjeti, "Highperformance adaptive perturb and observe MPPT technique for photovoltaic-based microgrids," IEEE Trans. Power Electron., vol.26, no.4, pp.1010-1021, 2011.

[20] F. Liu, S. Duan, F. Liu, B. Liu, and Y. Kang, "A variable step size INC MPPT method for PV systems," IEEE Trans. Ind. Electron., vol.55, no.7, pp.2622-2628, 2008.

[21] I. Buchman, "Batteries in a portable world: a handbook on rechargeable batteries for non-engineers," Cadex Electronics Inc., Richmond, 2001.

[22] J. Pinto, V. Monteiro, H. Gonçalves, and J. L. Afonso, "Onboard reconfigurable battery charger for electric vehicles with traction-toauxiliary mode," IEEE Trans. Veh. Technol., vol. 63, no. 3, pp. 1104 $1116,2014$.

[23] A. Timbus, M. Liserre, R. Teodorescu, P. Rodriguez, and F. Blaabjerg, "Evaluation of current controllers for distributed power generation systems," IEEE Trans. Power Electron., vol.24, 2009.

[24] S. Buso, L. Malesani, and P. Mattavelli, "Comparison of current control techniques for active filter applications," IEEE Trans. Ind. Electron., vol.45, no.5, pp.722-729, 1998.

[25] V. Monteiro, J. Pinto, and J. L. Afonso, "Operation modes for the electric vehicle in smart grids and smart homes: present and proposed modes," IEEE Trans. Veh. Technol., vol.65, no.3, pp.1007-1020, 2016.

[26] P. Cortes, M. P. Kazmierkowski, R. M. Kennel, D. E. Quevedo, and J. Rodríguez, "Predictive control in power electronics and drives," IEEE Trans. Ind. Electron., vol.55, no.12, pp.4312-4324, 2008.

[27] B. Exposto, R. Rodrigues, J. Pinto, V. Monteiro, D. Pedrosa, and J. L. Afonso, "Predictive control of a current-source inverter for solar photovoltaic grid interface," IEEE CPE International Conference on Compatibility and Power Electronics, pp. 113-118, 2015. 